\title{
Characterization of Putative Virulence Factors of Pseudomonas aeruginosa Strain RBS Isolated from a Saltern, Tunisia: Effect of Metal Ion Cofactors on the Structure and the Activity of LasB
}

\author{
E. Rigane $\mathbb{D}^{1},{ }^{1}$ R. Dutoit, ${ }^{2}$ S. Matthijs, ${ }^{2}$ N. Brandt, ${ }^{2}$ S. Flahaut, ${ }^{3}$ and K. S. Belghith ${ }^{1}$ \\ ${ }^{1}$ Laboratory of Plant Biotechnology, Faculty of Sciences of Sfax, University of Sfax, Route Sokra BP 1171, 3000 Sfax, Tunisia \\ ${ }^{2}$ Labiris Research Institute, Avenue Emile Gryzon 1, 1070 Brussels, Belgium \\ ${ }^{3}$ Laboratory of Applied Microbiology, EIB, Université Libre de Bruxelles, Avenue Emile Gryzon 1, 1070 Brussels, Belgium
}

Correspondence should be addressed to E. Rigane; riganemna@gmail.com

Received 10 February 2020; Revised 4 June 2020; Accepted 27 June 2020; Published 23 July 2020

Academic Editor: Maxim Golovkin

Copyright $\odot 2020$ E. Rigane et al. This is an open access article distributed under the Creative Commons Attribution License, which permits unrestricted use, distribution, and reproduction in any medium, provided the original work is properly cited.

\begin{abstract}
Pseudomonas aeruginosa is a ubiquitous Gram-negative bacterium able to survive in diverse environments such as soil, plants, freshwater, and seawater. P. aeruginosa can be an opportunistic pathogen to humans when their immune system is deficient. Its pathogenicity may be linked to the production of virulence factors. We isolated $P$. aeruginosa strain RBS from the saltern of Sfax in Tunisia. In this study, we characterized the halotolerance, antibiotic susceptibility, and some virulence factors of strain RBS. High $\mathrm{NaCl}$ concentrations inhibited growth and motility. However, biofilm formation was enhanced to protect bacteria against salt stress. Among the 18 antibiotics tested, quinolones and tetracycline showed a significant inhibitory effect on growth, motility, and biofilm formation of strain RBS. $\beta$-Lactams, however, did not have any inhibitory effect on neither bacterial growth nor motility. In some cases, resistance was due, in part, to biofilm formation. We also showed that RBS produces two proteases, LasB and AprA, which have been shown to be implicated in host infection. LasB was further characterized to study the role of metal ions in enzyme stability. It possesses two distinct metal ion-binding sites coordinating a calcium and a zinc ion. The effect of metal ion chelation was evaluated as well as substitutions of residues involved in metal ion binding. Impairing metal ion binding of LasB led to a loss of activity and a sharp decrease of stability. Our findings suggest that the binding of both metal ions is interdependent as the two metal ions' binding sites are linked via a hydrogen bond network.
\end{abstract}

\section{Introduction}

Pseudomonas aeruginosa is a ubiquitous, Gram-negative bacterium that thrives in soil and aquatic environments, playing important roles in the carbon and nitrogen cycles. P. aeruginosa is also found infecting plants, insects, fishes, and mammals [1]. During the last few decades, $P$. aeruginosa has become one of the most frequent causative agents of nosocomial infections in predisposed human subjects [2]. P. aeruginosa affects a wide category of patients convalescing in hospitals from, for instance, lung diseases, traumatized cornea, and burns. Because of its ability to grow and survive in various environmental conditions, $P$. aeruginosa infection becomes common and outbreaks of extreme drug-resistant strains are frequent among hospital wards and intensive care units [3].
In order to control and prevent these pseudomonal infections, understanding regulatory mechanisms governing virulence gene expression is crucial to develop alternative therapeutic interventions. $P$. aeruginosa produces a variety of virulence factors regulated by quorum sensing (QS): elastase (LasB), alkaline protease (AprA), protease A, exotoxin A, pyocyanin, and rhamnosyltransferase [4]. Recent studies have unveiled a hierarchical QS network in this pathogen, consisting of interconnected signaling pathways $[4,5]$. QS contributes to control the production of virulence factors, motility, motility-sessility switch, and biofilm development.

Bacterial motility is a critical aspect of $P$. aeruginosa pathogenesis. Swimming and swarming are the most described forms of motility [6]. These two movements present an essential mechanism for host colonization and biofilm formation 
[7]. During biofilm formation, $P$. aeruginosa cells attach to surfaces and form microcolonies, embedded in extracellular polymeric substances. Switching to a sessile lifestyle is a survival strategy for $P$. aeruginosa to evade stress and other adverse conditions [5]. The development of a biofilm has been characterized as an essential factor for antimicrobial resistance and tolerance [8]. Consequently, a significant rise in multidrug-resistant (MDR) strains makes the eradication of $P$. aeruginosa difficult [9]. In addition, $P$. aeruginosa utilizes intrinsic and acquired resistance mechanisms to counter the action of most antibiotics [10]. P. aeruginosa also produces the blue-green phenazine-derived pigment pyocyanin, involved in a variety of significant biological activities including gene expression and biofilm formation. For this reason, pyocyanin is considered both a virulence factor and a QS signaling molecule [11].

Several extracellular proteases are known to facilitate bacterial colonization by inducing damage to host tissue and actively subverting immune responses [12]. Two of these, AprA and LasB, are often implicated in P. aeruginosa infections. AprA degrades flagellin to escape the flagellinmediated immune response. LasB has a tissue-damage activity by degrading elastin and extracellular matrix components. In addition, it degrades various plasma proteins such as immunoglobulins. Both proteases are zinc metalloproteases that require calcium and zinc ions for stability and catalysis, respectively $[13,14]$. Owing to their unique chemical characteristics, metal ions fulfill and carry out diverse biological functions in enzymes. Metal binding is based on a specific geometry coordination imposed by the ligand residues [15]. Therefore, studying the interactions between the metal ions and their ligands is essential to understand their structural and functional properties [15]. Furthermore, how zinc and calcium affect the binding of each other has not been addressed in the literature.

In this study, we isolated a $P$. aeruginosa strain, called RBS, from the saltern of Sfax, Tunisia. The strain RBS was shown to be moderately halotolerant. Despite its isolation from a nonclinical environment, it is resistant to several antibiotics which prompted us to further characterize its virulence factors including pyocyanin, rhamnolipids, and secreted proteases. Our findings allowed the description and characterization of the key strategic adaptation mechanisms including motility, biofilm formation, and antibiotic resistance mechanisms. In the second part of this work, we focused on two secreted proteases, AprA, and LasB. The latter was further characterized to study the role of its metal ion cofactors. According to our results, the two metal ion centers of LasB are important for both the activity and stability. The interdependence of both metal ion centers could be due to a $\mathrm{H}$-bond networking connecting their ligands.

\section{Material and Methods}

2.1. Isolation of Strain RBS. Soil samples were collected from the artificial saltern of Sfax located in the southern coast of the Mediterranean Sea $\left(34^{\circ} 38^{\prime} \mathrm{N} 10^{\circ} 42^{\prime} \mathrm{E}\right)$ in Tunisia, to isolate protease-producing bacteria. Therefore, obtained bacterial strains were plated on skim milk agar plates ( $\mathrm{pH} 7)$, incubated at $30^{\circ} \mathrm{C}$, and screened for proteolytic activity after $18 \mathrm{~h}$. The colonies presenting a clear zone, resulting from milk casein hydrolysis, were evaluated as protease producers. For liquid culture, cells were grown for $38 \mathrm{~h}$ at $30^{\circ} \mathrm{C}$ in growth medium (GM) prepared as previously described [15] with slight modifications: $5 \mathrm{~g} / \mathrm{L}$ of casein supplemented with $10 \mathrm{~g} / \mathrm{L}$ of wheat bran, at $\mathrm{pH}$ 7.3. The supernatant was saturated using ammonium sulfate. All experiments were conducted in triplicate. The strain exhibiting the highest hydrolytic activity on milk casein in solid and liquid conditions was selected and named RBS.

2.2. Molecular Identification of Strain RBS. Total genomic DNA of strain RBS was extracted and purified with the QIAamp DNA Mini Kit (Qiagen, Germany). The almost complete 16S rRNA gene sequence (position 29 to 1522 in E. coli) of strain RBS was amplified with primers $\mathrm{pA}$ and $\mathrm{pH}$ [16]. Illumina paired-end sequencing was performed at the Oxford Genomics Center (UK). The $100 \mathrm{bp}$ reads were de novo assembled using Velvet [17] using a minimum contig length cutoff of $1 \mathrm{~kb}$ and various $k$-mer lengths. The Whole Genome Shotgun project has been deposited at DDBJ/ENA/GenBank under the accession WMEG00000000. The version described in this paper is version WMEG00000000.1. Annotation of open reading frames (ORF) was performed with the NCBI Prokaryotic Genome Annotation Pipeline (PGAP). Strain RBS was identified at the species level by the type strain genome server (TYGS) of DSMZ (https://tygs.dsmz.de/) [17].

2.3. Phenotypic Characterization of P. aeruginosa Strain RBS. To study the halotolerance of strain RBS, the growth, motility, and biofilm formation assays were carried out in the presence of $\mathrm{NaCl}$ at different concentrations (from 0.2 to $1 \mathrm{M}$ ). First, the growth of strain RBS was assessed at $30^{\circ} \mathrm{C}$ in Luria Bertani (LB) medium with increasing $\mathrm{NaCl}$ concentrations. Measurements of $\mathrm{OD}_{600}$ were done after $24 \mathrm{~h}$ of incubation. Motility assays were performed in LB medium ( $0.3 \%$ agar) [6] and M9 Minimal Medium (M9) (0.6\% agar) [18] for swimming and swarming assays, respectively. To assess the influence of $\mathrm{NaCl}$ on motility, $\mathrm{NaCl}$ was added to a concentration of up to $0.7 \mathrm{M}$. Twenty $\mathrm{mL}$ plates of either $\mathrm{LB}$ or M9 were poured and allowed to cool and solidify for, respectively, 20 and $30 \mathrm{~min}$. Subsequently, five $\mu \mathrm{L}$ of an overnight culture of strain RBS at an $\mathrm{OD}_{600}$ of 0.4 was deposited at the center of each plate. The plates were then incubated at $30^{\circ} \mathrm{C}$ for $18 \mathrm{~h}$. Three technical replicates were performed for each condition. The percentage (\%) of surface covered in the swarming and swimming assays was measured using ImageJ software, and values were normalized to the control grown in the absence of $\mathrm{NaCl}$.

Biofilm formation was tested as described previously [19]. Cultures were incubated for $24 \mathrm{~h}$ at $30^{\circ} \mathrm{C}$. The biofilm left adhered to the wells was stained by adding $200 \mu \mathrm{L}$ of $0.15 \%(\mathrm{v} / \mathrm{v})$ safranin and incubated for $10 \mathrm{~min}$ at room temperature. To solubilize the safranin stain retained by the biofilm, $150 \mu \mathrm{L}$ of acetic acid $33 \%(v / v)$ was added to each well. The absorbance of the formed biofilm was measured at $531 \mathrm{~nm}$ against a blank (acetic acid) and then normalized to 
biomass $\left(\mathrm{OD}_{600}\right)$. The biofilm development of strain RBS in the presence of $\mathrm{NaCl}$ was evaluated in increasing $\mathrm{NaCl}$ concentrations (from 0 to $1 \mathrm{M}$ ).

The susceptibility of RBS to antibiotics was determined by the disc agar diffusion (DAD) technique according to Bauer et al. [20]. An overnight culture was used to inoculate agar plates $\left(\mathrm{OD}_{600}\right.$ of 0.5). Filter paper discs of $6 \mathrm{~mm}$ diameter (GE Healthcare Life Sciences) were used to study bacterial resistance or susceptibility to 18 antibiotics: six $\beta$-lactam antibiotics (ampicillin, carbenicillin, cephalothin, neomycin, oxacillin, and penicillin), three aminoglycosides (gentamicin, kanamycin, and streptomycin), three quinolones (ciprofloxacin, nalidixic acid, and norfloxacin), vancomycin (glycopeptide), lincomycin (lincosamide class), erythromycin (macrolide), tetracycline (tetracycline class), and two miscellaneous agents (chloramphenicol and trimethoprim). The diameter of the bacterial growth inhibition zone surrounding the disc was accurately measured manually and compared to the European Committee for Antimicrobial Susceptibility Testing (EUCAST) guidelines.

The effect of antibiotics on motility of strain RBS was evaluated in the presence of ampicillin, chloramphenicol, kanamycin and tetracycline $(10,25$, and $50 \mu \mathrm{g} / \mathrm{mL})$, and streptomycin $(2.5,5$, and $10 \mu \mathrm{g} / \mathrm{mL})$. Motility media were autoclaved and placed to cool till $56^{\circ} \mathrm{C}$. Antibiotics were then added at the appropriate concentrations. The effect of antibiotics on biofilm formation of the strain RBS was assessed by incorporating different antibiotics at different concentrations in biofilm medium: ampicillin, streptomycin, and tetracycline $(5,10$, and $25 \mu \mathrm{g} / \mathrm{mL})$, kanamycin $(25,50$, and $100 \mu \mathrm{g} / \mathrm{mL})$, and chloramphenicol $(5,10,25$, and $50 \mu \mathrm{g} / \mathrm{mL})$.

The production of pyocyanin was assayed on Pseudomonas $\mathrm{P}$ agar (ThermoFisher Scientific) inoculated with an overnight culture of strain RBS and incubated for $48 \mathrm{~h}$ at $30^{\circ} \mathrm{C}$. The production and quantification of rhamnolipids (RHL) were carried out according to a methylene-bluebased quantification procedure described previously [21].

\subsection{Production, Purification, and MS Identification of LasB} and AprA. A cell-free supernatant sample was collected from an RBS culture grown for $36 \mathrm{~h}$ in LB supplemented with $10 \mathrm{~g}$ casamino acids (Difco). Cells were pelleted by centrifuging at $5,500 \times g$. The supernatant was collected and precipitated by adding ammonium sulfate at $65 \%$ of saturation. The obtained pellet (centrifuged at $18,000 \times g$ for $15 \mathrm{~min}$ ) was then dialyzed against $20 \mathrm{mM}$ sodium phosphate buffer $\mathrm{pH} 7.2$ (buffer A). The protease purification was carried out by means of an anionic exchange chromatography using a Source 15Q resin (GE Healthcare, Tricorn 10/150 column). The column was equilibrated with buffer A prior to the purification. The elution was performed using a gradient step from 0 to $1 \mathrm{M} \mathrm{NaCl}$ in a ten-column volume. Fractions were analyzed by SDSPAGE and caseinolytic activity assay [22]. Fractions containing proteolytic activity were pooled and concentrated using Amicon ultrafiltration units of $10 \mathrm{kDa}$ cutoff (Merck Millipore). Produced proteases were identified by LC-ESI-MS/MS analysis from a Coomassie Blue-stained gel (GIGA Proteomics Facility, University of Liège, Belgium). Zymogram analysis was performed according to Abcam's protocols.
2.5. Cloning of lasB. A codon-optimized synthetic gene (GeneArt-ThermoFisher Scientific) was used for the heterologous expression of lasB in Escherichia coli. The gene was amplified by PCR using specific primers $\left(5^{\prime}\right.$-ATTATTCAT ATGAAATACCTGCTGCCGACCGCTGCTGCTGGTCT GCTGCTCCTCGCTGCCCAGCCGGCGATGGCCGCCG AAGCCGGTGGTCCTGG-3 'and 5 '-AATAATCTCGA GTTACAGTGCGCTCGGACAGGTAACA-3') using Pfu DNA-polymerase (ThermoFisher Scientific). The amplified PCR product was cloned in the pJET1.2/blunt vector (ThermoFisher Scientific) prior to sequencing. The las $B$ gene was then excised by digesting with NdeI and XhoI and cloned into the pET30b expression vector (Novagen) using T4 DNA ligase (ThermoFisher Scientific). The plasmid sequences were verified by sequencing (Genetic Service Facility, University of Antwerp). In order to examine the role of calcium and zinc ions in catalysis and stability, substitutions of ion ligands in alanine and/or isomeric amino acids were carried out using synthetic genes (GeneArt, ThermoFisher Scientific). The mutated genes were subcloned into pET30b expression vector. The E. coli strain MC1061 was used for gene cloning.

2.6. Production and Purification of Recombinant Proteases. The E. coli strain BL21 was used for recombinant production of LasB. Cells were grown in 1.5 L of ZYM broth [23] containing $50 \mu \mathrm{g} / \mathrm{mL}$ kanamycin. After $24 \mathrm{~h}$ of incubation, both culture supernatant and cell pellet were collected by centrifuging at $9,000 \times g, 4^{\circ} \mathrm{C}$ for $30 \mathrm{~min}$. The cell pellet was washed twice with $50 \mathrm{mM}$ potassium phosphate buffer pH 6.0 and then resuspended in the same buffer. The periplasmic fraction was prepared following the protocol developed by Piwpankaew et al. [24] with slight modifications. Cells were resuspended in $100 \mathrm{mM}$ MOPS and $0.5 \mathrm{M}$ sucrose, $\mathrm{pH}$ 8. After incubating for $5 \mathrm{~min}$ on ice, cells were pelleted by centrifuging at $9,000 \times g$ for $15 \mathrm{~min}$ and resuspended in $1 \mathrm{mM} \mathrm{MgCl}$. The supernatant was incubated for $5 \mathrm{~min}$ on ice and then collected by centrifugation and neutralized with $40 \mathrm{mM}$ MOPS buffer supplemented with EDTA-free Protease Inhibitor (Roche Applied Science).

2.7. Protease Activity Assays. Four DQ-substrates (ThermoFisher Scientific) were used to determine the specific activity of purified proteases against different natural substrates: DQgelatin (from pig skin), DQ-collagen type I (from bovine skin), DQ-collagen type IV (from human placenta), and DQ-elastin (from bovine neck ligament). Activity assays were carried out in a black 96-well microplate (Corning) according to the manufacturer's recommendations: $0.7 \mu \mathrm{g} / \mathrm{mL}$ of enzyme was incubated in the presence of $100 \mu \mathrm{g} / \mathrm{mL}$ DQ-gelatin, $100 \mu \mathrm{g} / \mathrm{mL}$ DQ-collagen types I and IV, and $25 \mu \mathrm{g} / \mathrm{mL}$ DQ-elastin diluted in $1 \mathrm{X}$ reaction buffer. This buffer is composed of $0.5 \mathrm{M}$ Tris- $\mathrm{HCl}, 1.5 \mathrm{M} \mathrm{NaCl}, 50 \mathrm{mM} \mathrm{CaCl}_{2}$, and $2 \mathrm{mM}$ sodium azide, $\mathrm{pH} 7.6$ (for DQ-gelatin and DQcollagen types I and IV), and $1 \mathrm{M}$ Tris- $\mathrm{HCl}$ and $2 \mathrm{mM}$ sodium azide, $\mathrm{pH} 8.0$ (for DQ-elastin), in a reaction volume of $80 \mu \mathrm{L}$. Fluorescence was measured every $30 \mathrm{~s}$ for $20 \mathrm{~min}$ at $40^{\circ} \mathrm{C}$ on a Spectra Max M5 Multi-Mode Microplate Reader (Molecular Devices) with excitation and emission wavelength set at $495 \mathrm{~nm}$ and $515 \mathrm{~nm}$, respectively. The data were 
corrected by subtracting the negative control fluorescence. A collagenase type IV from Clostridium histolyticum was used as positive control for assays with DQ-gelatin and DQcollagen types I and IV while an elastase from Sus scrofa pancreas served as a positive control with DQ-elastin as substrate. All measurements were carried on triplicate. The maximal velocity $\left(V_{\max }\right)$ and Michaelis constant $\left(K_{\mathrm{m}}\right)$ were determined for DQ-gelatin and DQ-elastin as substrate using GraphPad Prism 6.01.

For determining the optimum $\mathrm{pH}$ of the enzyme, the protease activity was performed by using glycine- $\mathrm{HCl}(\mathrm{pH} 5.0)$, sodium phosphate ( $\mathrm{pH} 6.0-8.0)$, Tris- $\mathrm{HCl}$ ( $\mathrm{pH} 8.0-9.0)$, glycine- $\mathrm{NaOH}$ ( $\mathrm{pH} 9.0-11.0$ ), and $\mathrm{Na}_{2} \mathrm{HPO}_{4}-\mathrm{NaOH}(\mathrm{pH} 11)$ buffer at $0.1 \mathrm{M}$ containing $1 \%$ casein. The enzyme was incubated in various buffer solutions ( $\mathrm{pH} 3-13)$ at room temperature for $2 \mathrm{~h}$, and the residual activity was determined in standard experimental conditions. The effect of temperature on the enzyme activity was determined by measuring the enzyme activity on $1 \%$ casein in phosphate buffer $(40 \mathrm{mM}$, $\mathrm{pH}$ 8.0) for $10 \mathrm{~min}$ at different temperatures, ranging from $30^{\circ} \mathrm{C}$ to $80^{\circ} \mathrm{C}$. The nonheated enzyme was considered the control (100\% activity).

The susceptibility of LasB to inhibitors was determined using phenylmethylsulfonyl fluoride (PMSF), bestatin, ethylenediaminetetraacetic acid (EDTA), ethylene glycol-bis ( $\beta$-aminoethyl ether)-N,N,N ${ }^{\prime}, \mathrm{N}^{\prime}$-tetraacetic acid (EGTA), 1, 10-phenanthroline, diethylenetriaminepentaacetic acid (DTPA), and $\beta$-mercaptoethanol. The residual enzymatic activity was measured after incubating $25 \mu \mathrm{M}$ LasB with two doses of inhibitors, 1 and $5 \mathrm{mM}$, at $30^{\circ} \mathrm{C}$ for $30 \mathrm{~min}$. The effect of metal ion on LasB activity was investigated by incubating LasB $(25 \mu \mathrm{M})$ with two doses, $1 \mathrm{mM}$ and $5 \mathrm{mM}$, of $\mathrm{CaCl}_{2}$, $\mathrm{CoCl}_{2}$, and $\mathrm{ZnSO}_{4}$ at room temperature for $30 \mathrm{~min}$. The activity of LasB without any treatment was taken as $100 \%$.

2.8. Thermal Shift Assay (TSA). LasB was diluted to $30 \mu \mathrm{M}$ in $20 \mathrm{mM}$ MOPS pH 7.2, Sypro Orange 5X (ThermoFisher Scientific) with or without EDTA, EGTA, and 1,10-phenanthroline $(300 \mu \mathrm{M})$, as described previously [25]. The samples were distributed in a PCR multistrip $(20 \mu \mathrm{L}$ in each well). TSA was carried out using a StepOnePlus Real-Time PCR System (ThermoFisher Scientific) with a temperature gradient from $15^{\circ} \mathrm{C}$ to $99^{\circ} \mathrm{C}$ at $+0.4^{\circ} \mathrm{C} / \mathrm{min}$ ramp. All experiments were performed in duplicate. The wavelengths for excitation and emission were 490 and $575 \mathrm{~nm}$, respectively. The derivative of the fluorescence curve was used to determine the melting temperature $\left(T_{\mathrm{m}}\right)$.

2.9. Statistical Analysis. The Graphpad Prism software (version 6.01) was used for statistical analysis. Each experiment was performed at least 3 times, and the data were calculated as means $\pm \mathrm{SD}$ (standard deviation). One-way parametric ANOVA was performed to compare means, in accordance with the Brown-Forsythe law and Holm-Sidak test.

\section{Results}

3.1. Isolation of the Strain RBS and Characterization of Its Halotolerance. Samples were collected from an artificial salt- ern of Sfax, Tunisia, in April 2015. Three proteolytic strains were isolated from the saltern pond $(90.7 \pm 19.1 \mathrm{psu})$. Strain RBS showed the largest clear hydrolysis zone using casein as substrate (see Figure S1 in the Supplementary Materials for casein hydrolysis zone), with the highest specific activity (1773.45 U/g of protein). Its halotolerance was evaluated by growing cells in LB medium with increasing $\mathrm{NaCl}$ concentrations. Biomass was significantly enhanced at concentrations of up to $0.7 \mathrm{M} \mathrm{NaCl}$, compared to growth in the absence of salt $(P<0.0001)$ (Figure $1(\mathrm{a}))$. At these concentrations, the swarming state of cells was more important than the swimming state (Figure 1(b)). At higher concentrations $(0.9$ and $1 \mathrm{M})$, biomass and motility decreased significantly $(P<0.0001)$, while biofilm formation was significantly enhanced compared to biofilm in the absence of $\mathrm{NaCl}(P<0.0001)$ (Figure $1(\mathrm{c}))$. These results showed the shift of strain RBS population from swimming to swarming (movement in a group) and the subsequent formation of microcolonies embedded in the biofilm matrix.

3.2. Molecular Identification of Strain RBS. The genome of RBS has a total size of $6.66 \mathrm{Mbp}$ with 5,696 genes, of which 5,584 are coding genes. Blast analysis of the 16S rRNA gene (MT031760) identified strain RBS as P. aeruginosa. Analysis of the genome at the type strain genome server (TYGS) confirmed the species identification.

3.3. Antibiotic Resistance of $P$. aeruginosa RBS. The $P$. aeruginosa strain RBS displayed a broad-range resistance to antibiotics, notably against $\beta$-lactam antibiotics, vancomycin, trimethoprim, and erythromycin (Table 1). Gentamycin, kanamycin, and streptomycin were the most effective antibiotics against strain RBS with a growth inhibition zone of 20, 15 , and $12 \mathrm{~mm}$ diameter, respectively. For the quinolones, an overall notable sensitivity was recorded against nalidixic acid (7 $\mathrm{mm})$ and ciprofloxacin $(15 \mathrm{~mm})$. The sensitivity to quinolones is due in part to the absence of single nucleotide mutation in gyrA (codon 83, T83I), parC (codon 87, S87L), and mexR (codon 126, E126V), coding the DNA gyrase subunit A, topoisomerase IV, and MexAB-OprM pump, respectively. The genome sequence of strain RBS does not show any mutation in gyrA and parC, but mexR displays the mutation of codon 126. This mutation, however, is not thought to be linked to quinolone resistance as reported previously [26].

3.4. Effect of Antibiotics on Motility and Biofilm Formation of P. aeruginosa RBS. High doses of chloramphenicol, tetracycline, and streptomycin $(25 \mu \mathrm{g} / \mathrm{mL})$ and kanamycin $(50 \mu \mathrm{g} / \mathrm{mL})$ significantly inhibited $P$. aeruginosa RBS growth in liquid medium (Figure 2). Ampicillin had no effect on cell growth, even at a concentration of $25 \mu \mathrm{g} / \mathrm{mL}$. This resistance can probably be attributed to the production of $\beta$-lactamases, since the strain RBS genome contains $\beta$-lactamases coding genes.

Regarding its motility, $P$. aeruginosa strain RBS had a differential response to antibiotic exposure. Swimming and swarming motility was dramatically hampered by tetracycline and chloramphenicol at a concentration ranging from $10 \mu \mathrm{g} / \mathrm{mL}$ to $50 \mu \mathrm{g} / \mathrm{mL},(P<0.0001)$ (Figures $3(\mathrm{a})$ and $3(\mathrm{~b})$ ). 


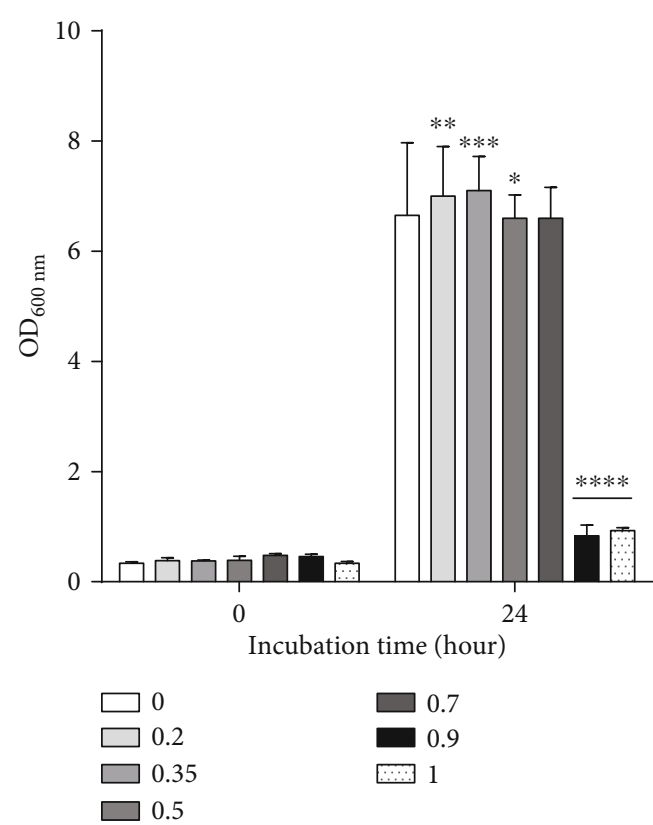

(a)

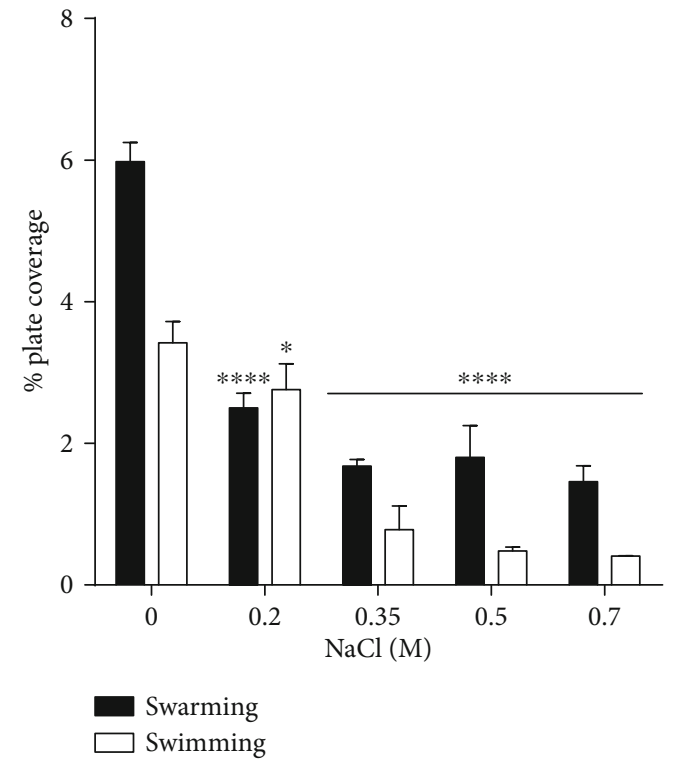

(b)

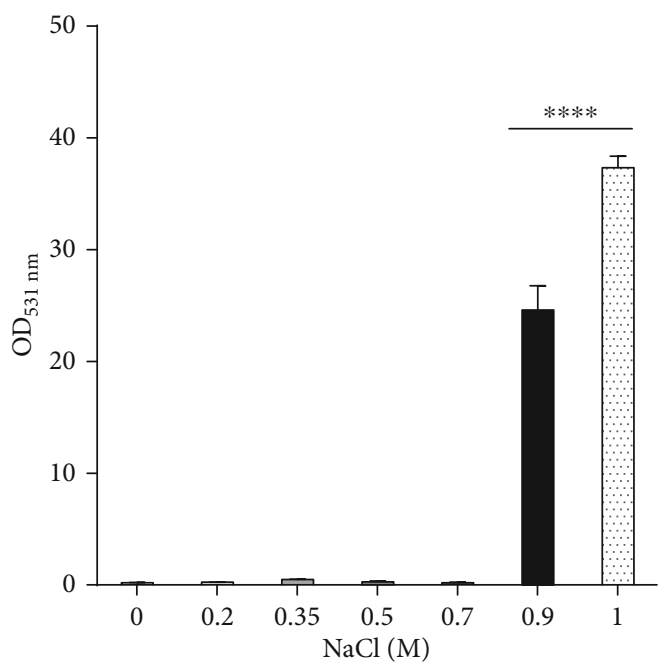

(c)

Figure 1: Effect of sodium chloride $(\mathrm{NaCl})$ on P. aeruginosa strain RBS (a) growth, (b) motility, and (c) biofilm formation. Various concentrations of $\mathrm{NaCl}$ ranging from 0 to $1 \mathrm{M}$ were tested to monitor its effect on growth and biofilm formation. For motility assays, $\mathrm{NaCl}$ was added at a concentration ranging from 0 to $0.7 \mathrm{M}$ in solid growth medium. The data of motility assays are expressed as plate coverage percentage. For biofilm formation, $\mathrm{OD}_{531}$ was normalized to biomass $\mathrm{OD}_{600}$. Values are expressed as means $\pm \mathrm{SD} .{ }^{*} P<0.05,{ }^{* *} P<0.01$, ${ }^{* * *} P<0.001$, and ${ }^{* * * *} P<0.0001$ vs. control.

Kanamycin significantly inhibited swimming motility at a low concentration $(10 \mu \mathrm{g} / \mathrm{mL}),(P<0.0001)$ (Figure $3(\mathrm{a}))$. The swarming phenotype, however, was reduced at a higher concentration of kanamycin (Figure 3(b)). In the presence of streptomycin $(2.5 \mu \mathrm{g} / \mathrm{mL})$, swarming was significantly enhanced $(P<0.0001)$, (Figure $3(\mathrm{~b}))$, while in higher concentrations, RBS cells shifted to swimming state to overcome the presence of high streptomycin concentrations (Figure 3(a)). When P. aeruginosa RBS was exposed to ampicillin, the swimming motility was decreased while the swarming motility was significantly increased by ampicillin, from $11.81 \%$ of plate coverage without antibiotic to $24.78 \%$ with $50 \mu \mathrm{g} / \mathrm{mL}$ ampicillin.
The five tested antibiotics, however, promoted biofilm formation in P. aeruginosa strain RBS (Figure 4) compared to the control culture without antibiotic. Biofilm formation was especially high in the presence of $100 \mu \mathrm{g} / \mathrm{mL}$ of chloramphenicol $\left(\mathrm{OD}_{531}=6.3\right)$. Nevertheless, biofilm formation of $P$. aeruginosa strain RBS was inhibited at the highest concentration of kanamycin $(100 \mu \mathrm{g} / \mathrm{mL})$ and streptomycin $(25 \mu \mathrm{g} / \mathrm{mL})$ (Figure 4). Enhanced biofilm production is a common strategy to tolerate antibiotics in $P$. aeruginosa as the extracellular matrix provides a reduced permeability to antibiotics [27]. Under the exposure to antibiotics, RBS cells shift from a free state (swimming and swarming) to a sessile 
TABle 1: Susceptibility of Pseudomonas aeruginosa strain RBS to various antibiotics determined using disc agar diffusion method.

\begin{tabular}{lccc}
\hline Antibiotic class & Antibiotic & $\begin{array}{c}\text { Disc } \\
\text { content }(\mu \mathrm{g})^{\mathrm{a}}\end{array}$ & $\begin{array}{c}\text { Zone } \\
\text { diameter } \\
(\mathrm{mm})\end{array}$ \\
\hline Carbenicillin & 100 & 0 \\
antibiotics & Penicillin & 10 & 0 \\
& Ampicillin & 10 & 0 \\
& Cephalothin & 30 & 0 \\
& Oxacillin & 1 & 0 \\
Aminoglycosides & Neomycin & 30 & 11 \\
\hline \multirow{3}{*}{ Quinolones } & Streptomycin & 10 & 12 \\
& Gentamycin & 50 & 15 \\
\hline Tetracycline & Norfloxacin & 10 & 20 \\
Lincosamide & Nalidixic acid & 30 & 0 \\
Glycopeptide & Ciprofloxacin & 25 & 7 \\
Miscellaneous & Lincomycin & 10 & 15 \\
agents & Vancomycin & 30 & 0 \\
Macrolide & Chloramphenicol & 10 & 0 \\
\hline & Erythromycin & 15 & 0 \\
\hline
\end{tabular}

${ }^{\mathrm{a}}$ Except penicillin (U).

state to overcome the exposure to antibiotics. Indeed, efflux systems are upregulated in biofilms, increasing tolerance to antibiotics [28].

3.5. Virulence Factors of P. aeruginosa Strain RBS. P. aeruginosa secretes various redox-active phenazine compounds, the most well-studied being pyocyanin. The pyocyanin production was evaluated on Pseudomonas $\mathrm{P}$ agar medium. After $48 \mathrm{~h}$, a green pigment diffused into the agar, indicating the production of pyocyanin (see Figure S2 in the Supplementary Materials for pyocyanin production). The production of RHL in $P$. aeruginosa strain RBS was assessed using the methylene blue complexation method. Under these conditions (M9 medium, at $30^{\circ} \mathrm{C}$ for $24 \mathrm{~h}$ ), about $94 \mu \mathrm{g}$ of RHL was produced per milliliter of culture. The production of rhamnolipids is associated with the expression of pyocyanin. The production of proteases is a well-known virulence trait of $P$. aeruginosa [29]. As RBS displayed a strong hydrolytic activity on casein (see Figure S1 in the Supplementary Materials for casein hydrolysis zone), the secreted proteases were identified by SDS-PAGE and LC-ESI-MS/MS. On SDS-PAGE gel, two major bands were observed at $33 \mathrm{kDa}$ (elastase, LasB) and $50 \mathrm{kDa}$ (alkaline protease, AprA) (see Figure S3-A in the Supplementary Materials for SDS-PAGE gel) that has been determined by LC-ESI-MS/MS, with pI 6.3 and 4.1, respectively. Based on their $\mathrm{pI}$, an anionic chromatography was used to separate LasB and AprA, at pH 7.2. AprA was eluted at 0.65 and $0.75 \mathrm{M} \mathrm{NaCl}$ while LasB was not retained on the chromatography media. The proteolytic activity of both enzymes was assessed by casein hydrolysis assay and zymogram (see Figure S3-B in the Supplementary Materials for zymogram). Specific activity of purified LasB and AprA against casein was 6843 and $828.5 \mathrm{IU} / \mathrm{mg}$, respectively.

3.6. Biochemical Characterization of Recombinant LasB. LasB and AprA were produced recombinantly in E. coli for further characterization. Unfortunately, AprA failed to be secreted and was present in the insoluble cell fraction only (data not shown). For LasB, the periplasmic translocation was mediated via the secretion signal of PelB [30], making the purification of recombinant LasB possible from the periplasm by anionic chromatography. LasB displayed a proteolytic activity up to $80^{\circ} \mathrm{C}$, with a maximum at $40^{\circ} \mathrm{C}$ (Figure $5(\mathrm{a})$ ). A sharp decrease was observed from about $65^{\circ} \mathrm{C}$. LasB activity was assayed in a $\mathrm{pH}$ range from 4 to 11 and exhibited an optimum at pH 8 (Figure 5(b)).

The specificity of LasB was evaluated against four fluorescent-labelled substrates: DQ-elastin, DQ-collagen of types I and IV, and DQ-gelatin (Table 2). LasB displayed the highest specificity on gelatin substrate, which was expected as gelatin is the product of collagen denaturation. With the native substrates, LasB is more specific to elastin degradation than type I and IV collagens. Kinetic parameters, $k_{\text {cat }}$ and $K_{\mathrm{m}}$, were determined with DQ-elastin and DQgelatin as substrates. The hydrolysis rate of both substrates obeyed the Michaelis-Menten equation (see Figure S4 in the Supplementary Materials for Michaelis-Menten curve). Only apparent kinetic constants were determined due to the substrate solubility limitation. For DQ-gelatin degradation ( $\left.\mathrm{pH} 8.0,40^{\circ} \mathrm{C}\right), K_{\mathrm{m}}$ and $k_{\text {cat }}$ were $95 \mu \mathrm{g} / \mathrm{mL}$ and $588 \mathrm{~s}^{-1}$, respectively, while being $92 \mu \mathrm{g} / \mathrm{mL}$ and $0.17 \mathrm{~s}^{-1}$ for DQ-elastin hydrolysis.

3.7. The Role of Metal Ion Cofactors on LasB Activity and Stability. Several known protease inhibitors ( $\beta$-mercaptoethanol, DTPA, EDTA, EGTA, 1,10-phenanthroline, and PMSF) were tested on LasB (Table 3 ). The activity remained unaffected by PMSF, which is consistent with the absence of a catalytic serine residue. $\beta$-Mercaptoethanol increased slightly the activity, which may be due to the enzyme stabilization in the tested conditions. In the presence of EDTA and 1,10-phenanthroline at $5 \mathrm{mM}$, LasB retained only 56.2 and $26.0 \%$ of activity, respectively. The two other metal-chelating inhibitors, DTPA and EGTA, had an even more dramatic impact on elastase activity, being reduced to $11.5 \%$ and $3.4 \%$, respectively. Similar results were reported for AMPP, an elastase from $P$. aeruginosa [31]. Two variants affected in $\mathrm{Zn}^{2+}$ or $\mathrm{Ca}^{2+}$ binding were generated to evaluate the contribution of both ions to the LasB activity and stability. To impair the $\mathrm{Zn}^{2+}$ binding, His-140 and His-144 were substituted with an alanine residue (variant LasB_ $\mathrm{Zn}^{2+}$ ). For the $\mathrm{Ca}^{2+}$ binding, Asp-136, Glu-172, Glu-175, and Asp-183 were substituted with asparagine and glutamine residues (mutant LasB_Ca ${ }^{2+}$ ). After the purification of the two variants from E. coli periplasm, the enzymatic activities were assessed using DQ-gelatin as substrate. Both variants were inactive, suggesting that $\mathrm{Ca}^{2+}$ and $\mathrm{Zn}^{2+}$ could play an important role in the LasB activity. The contribution of $\mathrm{Ca}^{2+}$ and $\mathrm{Zn}^{2+}$ to the 


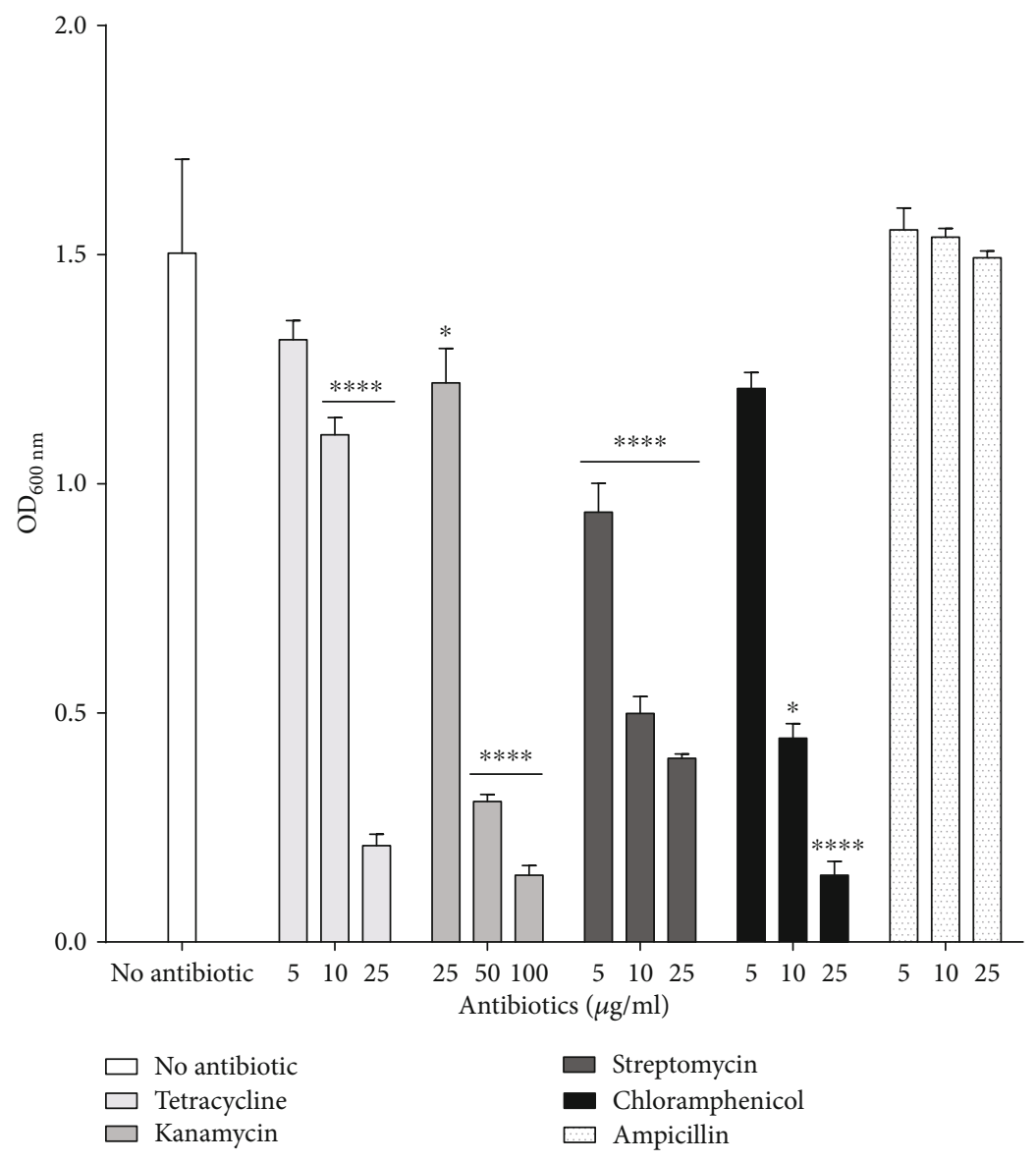

Figure 2: Influence of antibiotics on $P$. aeruginosa RBS growth. Tetracycline, kanamycin, chloramphenicol, streptomycin, and ampicillin were added to growth media at different concentrations. Growth was determined by following $\mathrm{OD}_{600}$ and normalized to strain RBS grown without antibiotic. Values are expressed as means $\pm \mathrm{SD} .{ }^{*} P<0.05,{ }^{* *} P<0.01,{ }^{* * *} P<0.001$, and ${ }^{* * * *} P<0.0001$ vs. control with $n=3$.

enzyme stability was determined by thermal shift assays using either the wild-type enzyme in presence of chelating agents or the metal-binding impaired variants.

Without any chelating agent, LasB had a $T_{\mathrm{m}}$ of $77.0^{\circ} \mathrm{C}$. In the presence of EDTA and 1,10-phenanthroline, a zinc specific chelator, the $T_{\mathrm{m}}$ values dropped to $54.8^{\circ} \mathrm{C}$ and $54.4^{\circ} \mathrm{C}$, respectively (Table 4). With EGTA, a calcium specific chelator, LasB had a $T_{\mathrm{m}}$ of $66.0^{\circ} \mathrm{C}$. The chelation of $\mathrm{Ca}^{2+}$ and $\mathrm{Zn}^{2+}$ could lead to a less stable "open" conformation of LasB, explaining the $T_{\mathrm{m}}$ drop in the presence of the chelator. As 1,10-phenanthroline had a greater impact on LasB stability than EGTA, one may suppose that $\mathrm{Zn}^{2+}$ is important for the stability in addition to its catalytic role. For mutants LasB_Ca ${ }^{2+}$ and LasB_Zn ${ }^{2+}$, measured $T_{\mathrm{m}}$ were similar, $47.4^{\circ} \mathrm{C}$ and $48.6^{\circ} \mathrm{C}$, respectively. This result suggests that both $\mathrm{Ca}^{2+}$ - and $\mathrm{Zn}^{2+}$ - binding sites are implicated in structure integrity. Based on TSA data, the binding of metal ions in Las $\mathrm{B}$ made the structure more stable, suggesting a possible reorganization of the active site pocket.

According to our results, impairing calcium or zinc binding had an impact on the LasB activity and stability. Based on LasB structure (PDB code $1 \mathrm{U} 4 \mathrm{G}$ ), both metal ion-binding sites are intertwined by a hydrogen bond network. The interactions between residues of the two binding sites were calcu- lated using PDB2PQR server [32]. His-140 and His-144 are in interaction with the neighbor amino acids Glu-141, Tyr155, Glu-164, and Asp-168. Glu-141 is the catalytic base, Tyr-155 is involved in substrate binding, and Glu-164 is the third $\mathrm{Zn}^{2+}$ ligand (Figure 6). Asp-168 is not directly involved in the catalytic site but it interacts with Arg-198 which is involved in substrate binding. The zinc-binding site is connected to the calcium-binding site via interactions involving Asp-136 and Glu-172. Indeed, there are two backbone-tobackbone interactions between Asp-136 and His-140 and between Glu-172 and Asp-168.

\section{Discussion}

The isolation of $P$. aeruginosa strain RBS from the saltern of Sfax raises questions about its origin. Indeed, the high metabolic versatility of $P$. aeruginosa allows its survival in a wide range of environments, including freshwater, wastewater, ocean, and soil. A human-related origin, however, cannot be excluded since $P$. aeruginosa has been found in sewage contaminated rivers [29]. Its occurrence in freshwater is often related to human activities, and therefore, a contamination of coastal water could be possible as shown previously [33]. Although the majority of epidemiological studies have 


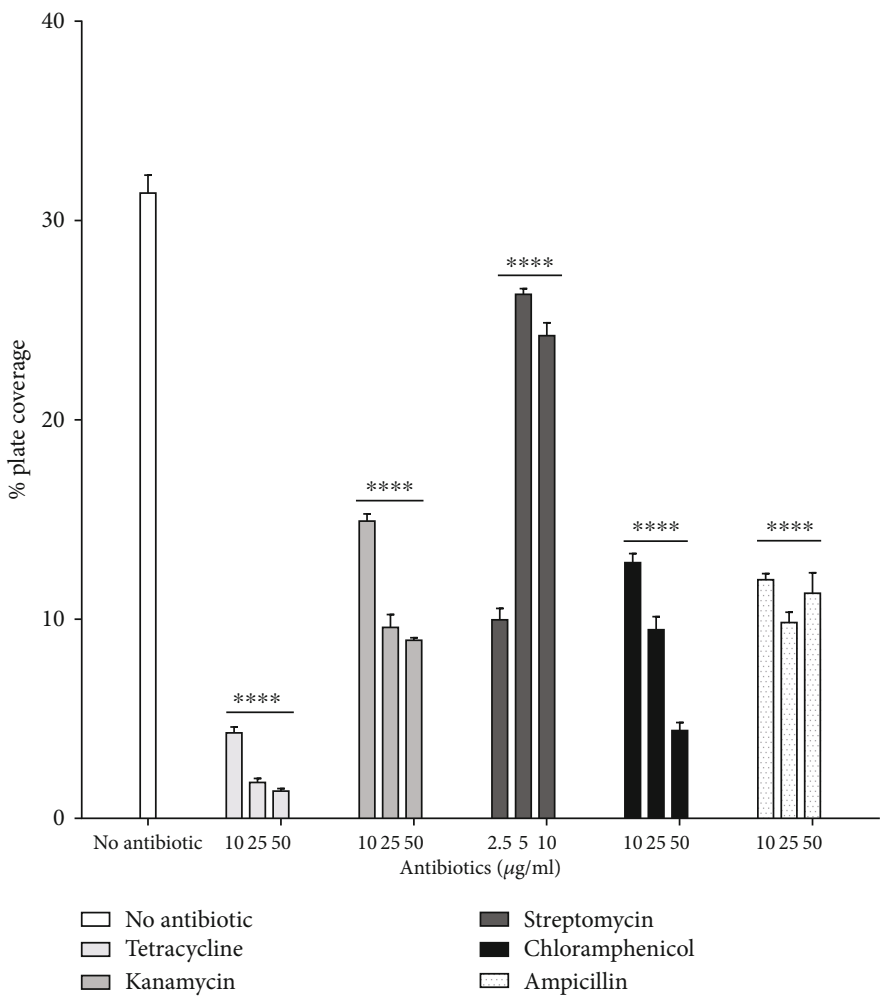

(a)

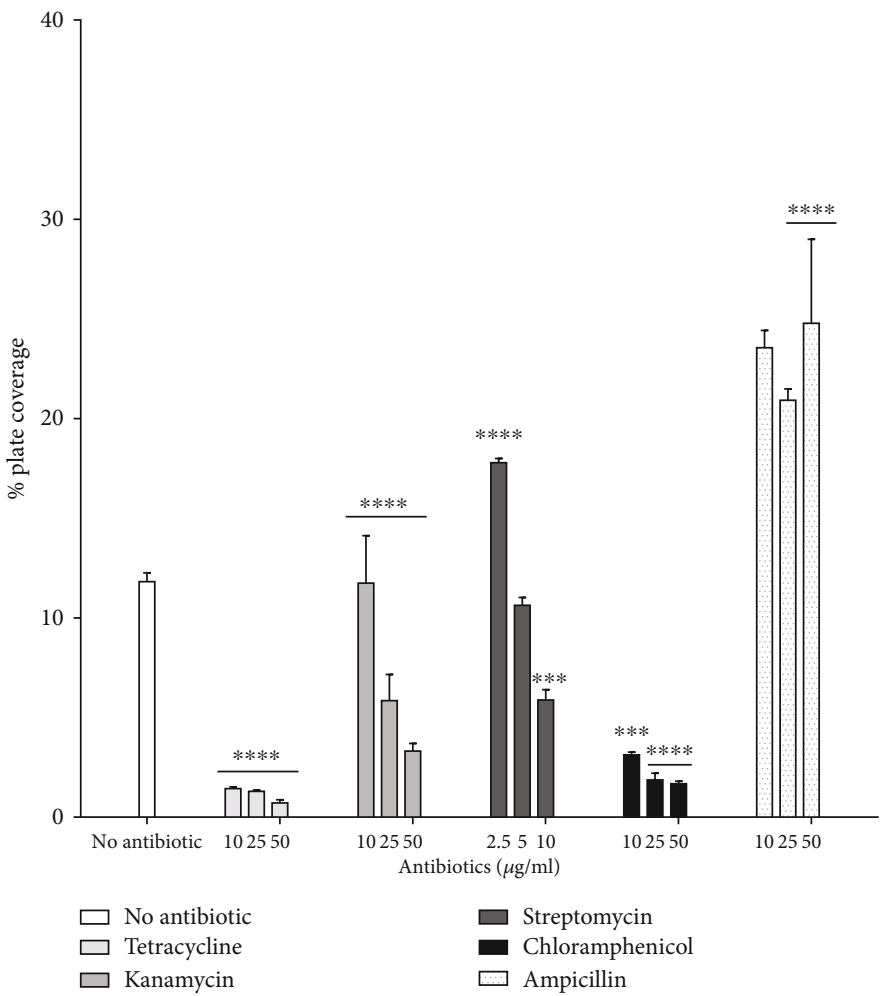

(b)

FIGURE 3: Effect of antibiotics on (a) swimming and (b) swarming of P. aeruginosa RBS cells. Tetracycline, kanamycin, chloramphenicol, streptomycin, and ampicillin were added at different concentrations to swimming and swarming agar media to determine their effect on motility. Growth was normalized to the control grown without antibiotic. Data are expressed as plate coverage percentage. Values are expressed as means $\pm \mathrm{SD}$. ${ }^{* * *} P<0.001,{ }^{* * * *} P<0.0001$ vs. control grown without antibiotic with $n=3$. 


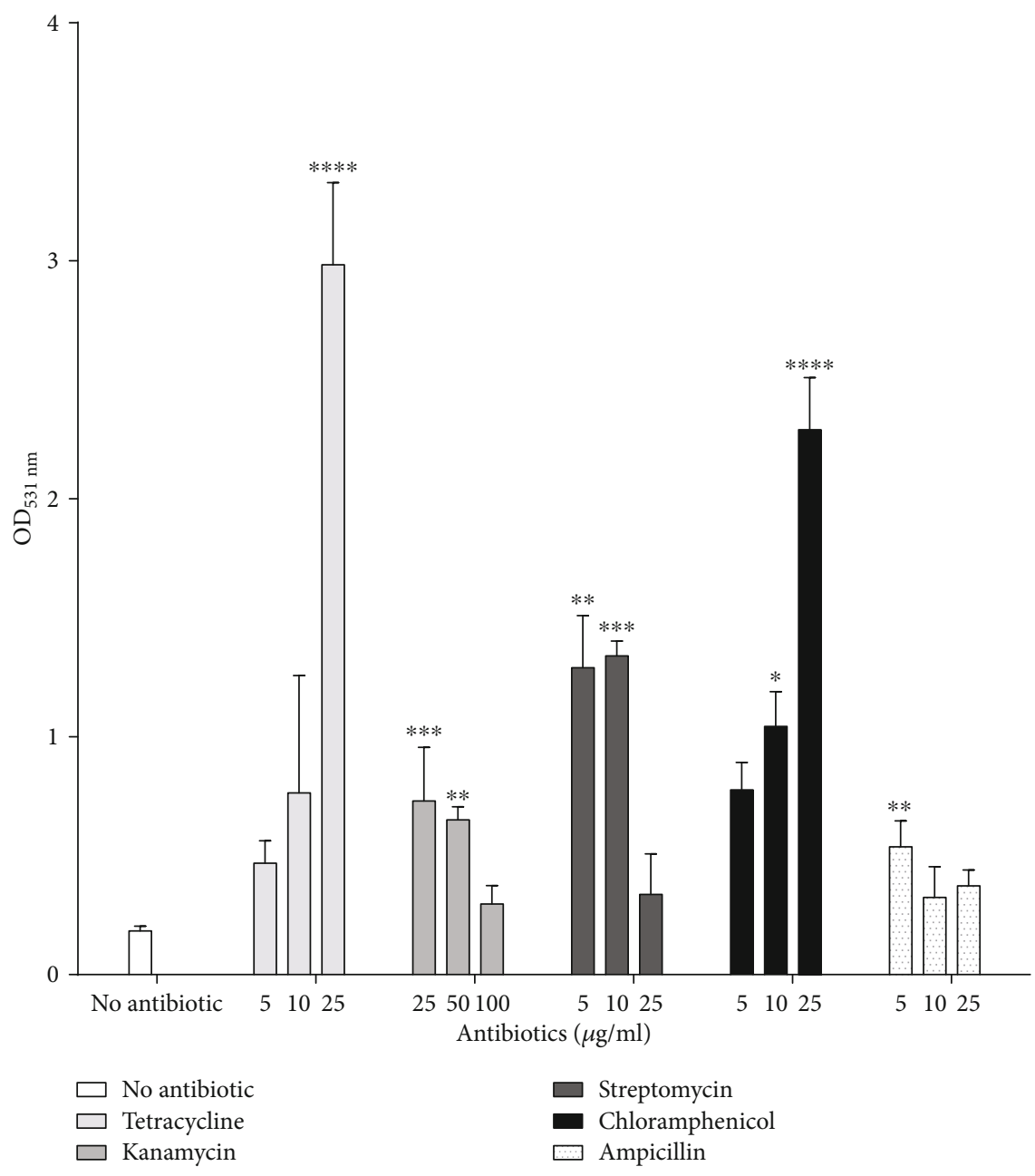

Figure 4: Influence of antibiotics on P. aeruginosa RBS biofilm formation. Tetracycline, kanamycin, chloramphenicol, streptomycin, and ampicillin were added at different concentrations to biofilm medium. Data are expressed as $\mathrm{OD}_{531}$ and normalized to $\mathrm{OD}_{600}$. Values are expressed as means \pm SD. ${ }^{*} P<0.05,{ }^{* *} P<0.01,{ }^{* * *} P<0.001$, and ${ }^{* * * *} P<0.0001$ vs. control with $n=3$.

focused on clinical rather than environmental isolates and research into the environmental distribution of strains is still limited [34], Rutherford et al. studied the prevalence of two genes coding effector proteins, exoS and exo $\mathrm{U}$, in the environment. The exoS gene is often found in strains isolated from natural environmental sites (e.g., plant, soil, and lakes), whereas exoU occurs in strains isolated from human activityrelated sites (e.g., drains and sinks). The genome of strain RBS harbored only exoS, suggesting its natural environmental origin [34].

Firstly, we evaluated the growth of the strain RBS in the presence of $\mathrm{NaCl}$. Its growth was enhanced in the presence of up to $0.7 \mathrm{M}$ of $\mathrm{NaCl}(41 \mathrm{~g} / \mathrm{L})$, a concentration close to seawater salinity $(40 \mathrm{~g} / \mathrm{L})[35]$. A loss of growth, however, was observed at higher salt concentrations $(0.9$ and $1 \mathrm{M} \mathrm{NaCl})$. This observation suggests that strain RBS is slightly halophilic. We assessed the effect of $\mathrm{NaCl}$ on the $P$. aeruginosa RBS motility. A sharp decrease of swimming motility was observed for $\mathrm{NaCl}$ concentrations above $0.5 \mathrm{M}$. At $0.7 \mathrm{M}$ $\mathrm{NaCl}$, most of the RBS population shifted to swarming movement. At a salt concentration of 0.9 and $1 \mathrm{M}$, the growth and motility were dramatically reduced, corroborating with bio- film formation. The shift from planktonic state to sessile lifestyle (biofilm) is also detected in some clinical strains as a strategy to escape some stresses, like antibiotic treatment during infection $[36,37]$. For this reason, we evaluated the susceptibility to antibiotics, in addition to halotolerance and motility, for $P$. aeruginosa RBS, as clues on its possible environmental origin.

Secondly, the antibiotic susceptibility of the strain RBS was tested against 18 antibiotics. The strain RBS showed susceptibility to aminoglycosides, chloramphenicol, ciprofloxacin, streptomycin, and tetracycline, but it is resistant to $\beta$ lactam antibiotics, vancomycin, trimethoprim, and erythromycin. Such an antibiotic response pattern has been reported for other marine Pseudomonas strains [38]. However, in the presence of kanamycin, ampicillin, and streptomycin, strain RBS displayed the same stress response: biofilm formation. The strain RBS displayed some physiological adaptations, including biofilm formation, to cope with high osmolality and antibiotics. Biofilm can be regarded as a protective hydrated microenvironment to sessile $P$. aeruginosa exposed to desiccation stress [39]. This intrinsic resistance mechanism ensures the survival of biofilm-embedded cells, by 


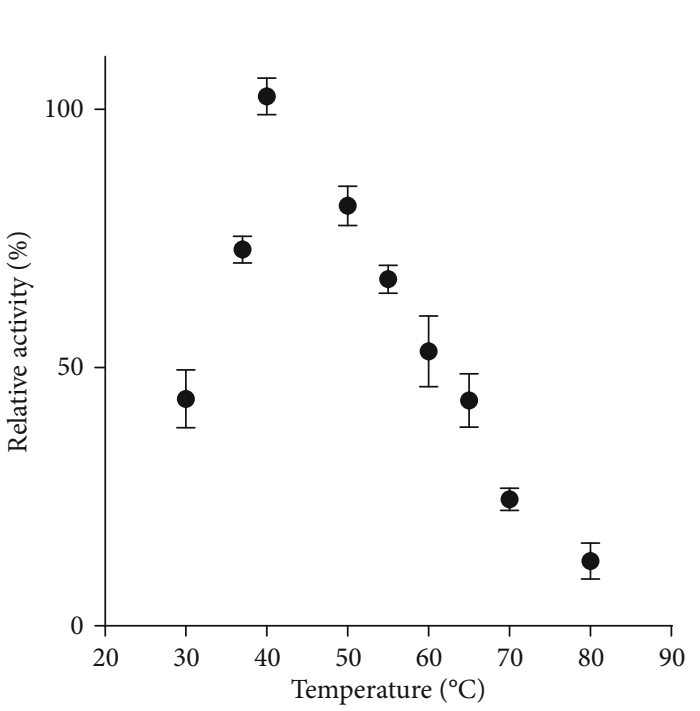

(a)

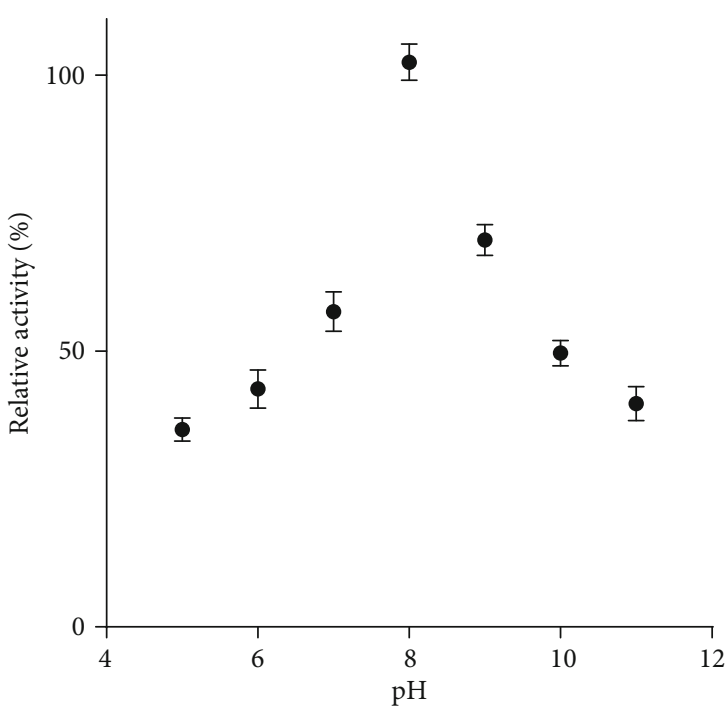

(b)

Figure 5: Influence of temperature (a) and $\mathrm{pH}(\mathrm{b})$ on the activity of recombinant LasB. The temperature profile was determined by assaying enzyme activity at different temperature values ranging from 30 to $80^{\circ} \mathrm{C}$. The $\mathrm{pH}$ optimum profile was determined at $40^{\circ} \mathrm{C}$ in different buffers. Error bars represent SD with $n=3$.

TABLE 2: Specific activity of LasB against DQ-elastin, DQ-gelatin, and DQ-collagen of types I and IV. Specific activity is expressed in fluorescence unit (FU) per enzyme concentration (nM) and second (s).

\begin{tabular}{lc}
\hline DQ-substrate & Specific activity $\left(\mathrm{FU} \mathrm{nM}^{-1} \mathrm{~s}^{-1}\right)$ \\
\hline DQ-elastin & 0.13 \\
DQ-collagen type I & 0.041 \\
DQ-collagen type IV & 0.025 \\
DQ-gelatin & 0.3 \\
\hline
\end{tabular}

TABLE 3: Influence of inhibitors on proteolytic activity of LasB. The tested inhibitors ( 1 and $5 \mathrm{mM}$ ) were phenylmethylsulfonyl fluoride (PMSF), ethylenediaminetetraacetic acid (EDTA), ethylene glycolbis( $\beta$-aminoethyl ether)- $\mathrm{N}, \mathrm{N}, \mathrm{N}^{\prime}, \mathrm{N}^{\prime}$-tetraacetic acid (EGTA), 1,10phenanthroline, diethylenetriaminepentaacetic acid 382 (DTPA), and $\beta$-mercaptoethanol. The activity is expressed as relative activity with the enzyme incubated without an inhibitor as $100 \%$ reference. Values are expressed as means $\pm \mathrm{SD}, n=3$.

\begin{tabular}{lcc}
\hline Inhibitor & $\begin{array}{c}\text { Relative activity (\%) } \\
\text { with } 1 \mathrm{mM} \text { inhibitor }\end{array}$ & $\begin{array}{c}\text { Relative activity (\%) } \\
\text { with } 5 \mathrm{mM} \text { inhibitor }\end{array}$ \\
\hline$\beta$-Mercaptoethanol & $117.0 \pm 1.2$ & $111.4 \pm 1.1$ \\
DTPA & $45.7 \pm 0.6$ & $11.5 \pm 1.8$ \\
EDTA & $84.20 \pm 0.6$ & $56.2 \pm 0.7$ \\
EGTA & $82.6 \pm 1.0$ & $3.4 \pm 0.4$ \\
1,10 -Phenanthroline & $33.9 \pm 1.0$ & $26.0 \pm 0.6$ \\
PMSF & $91.3 \pm 2.7$ & $121.5 \pm 1.6$ \\
\hline
\end{tabular}

reducing the diffusion of antibiotics or by the production of antibiotic degrading enzymes [40]. The phenotypic switch from a free-swimming planktonic lifestyle to biofilm sessility
TABLE 4: Thermal shift assay of inhibitor effect on LasB thermostability. Thermostability was determined by measuring the melting temperature $\left(T_{\mathrm{m}}\right)$. The tested inhibitors were ethylenediaminetetraacetic acid (EDTA), ethylene glycol-bis $(\beta$ aminoethyl ether)-N,N, $\mathrm{N}^{\prime}, \mathrm{N}^{\prime}$-tetraacetic acid (EGTA), and 1,10phenanthroline. Values are expressed as means \pm SD.

\begin{tabular}{lc}
\hline Inhibitor & $T_{\mathrm{m}}\left({ }^{\circ} \mathrm{C}\right)$ \\
\hline No chelating agent & $77.0 \pm 0.1$ \\
EDTA & $54.8 \pm 0.3$ \\
EGTA & $66.0 \pm 0.2$ \\
1,10-Phenanthroline & $54.4 \pm 0.1$ \\
\hline
\end{tabular}

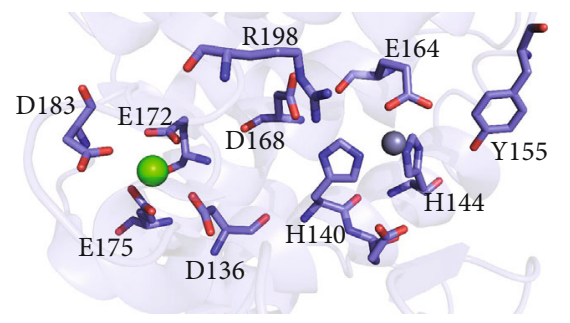

FIGURE 6: Close-up view into the active site of elastase (PDB 1U4G). Selected residues are displayed in stick representation, the calcium ion as a green sphere, and the zinc ion as a grey sphere.

is a common survival strategy of $P$. aeruginosa even though it lowers its virulence [5].

The ability of $P$. aeruginosa to resist antibiotics and environmental stresses makes the management of such infections a huge challenge in the healthcare settings. The pathogenic potential of $P$. aeruginosa, however, is not restricted to its metabolic/genetic versatility or its intrinsic/acquired antibiotic resistance. The production of a powerful arsenal of 
virulence factors (pigments, pili, flagellum, rhamnolipids, and hydrolytic enzymes) makes $P$. aeruginosa infections highly invasive and toxigenic. Consequently, the development of new therapeutic strategies against multidrugresistant $P$. aeruginosa is urgently needed. These strategies, however, should not affect the microbial growth as resistant subpopulations may appear during persistent infections [41]. Therefore, the attenuation or inhibition of these virulence factors emerges as an alternative and promising antivirulence therapy to overcome antibiotic-refractory infections caused by $P$. aeruginosa. Bacterial motility inhibition may be also an important therapy target, in order to avoid $P$. aeruginosa cell adherence to host tissues like the lungs. Elastase outstands as a pivotal virulence attribute during the infectious process, playing multifunctional roles in different aspects of the pathogen-host interaction and swarming motility [42]. Previous studies showed that inhibiting the expression/activity of bacterial virulence factors contributes to disarm the $P$. aeruginosa infective arsenal [41]. The virulence quenching by antivirulence compounds can allow the host immune system to prevent efficient bacterial colonization as well as to extinguish an established infection [43].

Finally, we characterized the elastase produced by the strain RBS. Since elastase is a metallopeptidase, it is important to understand and elucidate the roles of divalent metal ions (calcium and zinc) in the elastase stability and activity. For further biochemical characterization, LasB was recombinantly produced in $E$. coli. The effect of temperature and $\mathrm{pH}$ on the activity was studied as well as its substrate specificity. LasB displayed a maximal hydrolytic activity at $40^{\circ} \mathrm{C}$ and was active in a broad $\mathrm{pH}$ range (from 4 to 11 ). It hydrolyzed preferentially gelatin and elastin. The degradation of collagen is slower than that of gelatin and elastin since collagen is a denatured protein substrate. The catalytic activity of LasB depends on a zinc ion located in the active site. LasB possesses a second metal ion-binding site bridging a calcium ion. The role of the calcium ion could be linked to the stability of LasB [44]. Nevertheless, to our knowledge, there is no available study systematically investigating the effect of specific changes in the metal-containing active site (of both calcium and zinc) on the function of LasB. In this work, we addressed this issue by either using chelating agents or substituting the ligands of the calcium- and zinc-binding sites. In the presence of metallic chelators, EDTA, EGTA, and 1,10-phenanthroline, the activity and the thermal stability were extensively affected, suggesting that both $\mathrm{Zn}^{2+}$ and $\mathrm{Ca}^{2+}$ are involved in activity and stability. The mutation of calcium ligands led to the loss of proteolytic activity as well as to a drop of melting temperature. The same behavior was observed for the LasB_ $\mathrm{Zn}^{2+}$ mutant. These results suggest that both $\mathrm{Ca}^{2+}$ and $\mathrm{Zn}^{2+}$ are catalytically and structurally important or both metal ion-binding sites are interconnected.

According to the structure of LasB [13], a hydrogen bond network could link both metal ion-binding sites. The ligands involved in zinc binding are interconnected by hydrogen bonds to other important residues. His-140 interacts with His-223, a residue implicated in substrate binding. Glu-164 establishes hydrogen bonds with Tyr-155, Asp-168, Glu141, and Arg-198. Tyr-155 and Arg-198 are also involved in substrate binding while Glu-141 is the catalytic acid/base residue. His-140 is also connected to Arg-198 via its interaction with Asp-168. The $\mathrm{Zn}^{2+}$-binding site is probably connected to the $\mathrm{Ca}^{2+}$-binding site through two backbone-to-backbone interactions involving Asp-136/His-140 and Glu-172/Asp168. The zinc ion could also play a switcher role via the residues involved in its binding interacting with neighbor amino acids, like Glu-141, Asp-168, and Tyr-155. As previously reported for the zymogen form of matrix metalloproteinase-9 [45], the zinc ion has a structural function and a catalytic role. During the maturation of this protease, one of the ligands can release its interaction with the zinc ion, changing from a tetracoordination to a pentacoordination geometry. Such a coordination geometry swap turns the zinc ion function from a structural role to a catalytic role. To understand how metal ion may affect LasB structure, the apoform and transition state intermediates must be identified and studied.

\section{Conclusion}

The $P$. aeruginosa strain RBS was isolated from the saltern of Sfax in Tunisia. RBS is adapted to its saline environment but is also resistant to many antibiotics and produces several virulence factors (pyocyanin, rhamnolipids, LasB, and AprA). Consequently, the problem arises of how to deal with potential pathogen in the clinical environment. These factors could potentially participate in host infection and host immune component degradation. Their expression, however, depends on a pool of factors through the QS network [4]. But how the expression is induced remains elusive. We investigated the effect of metal ion cofactors (calcium and zinc ions) on the structure and the activity of LasB, a potential target for antivirulence therapies against $P$. aeruginosa infections. Our results suggest that both calcium and zinc ions could play a role in structure stability and activity. Based on available structural data, the two metal ion-binding sites seem to be connected via a hydrogen bond network involving several interrelated conserved residues.

\section{Data Availability}

All data are available in the manuscript and genomic database (for genomic sequence).

\section{Conflicts of Interest}

The authors declare that they have no conflict interest.

\section{Acknowledgments}

The research and publication of the article were funded by Labiris Research Institute.

\section{Supplementary Materials}

Figure S1: casein hydrolysis. Figure S2: pyocyanin production by $P$. aeruginosa RBS on Pseudomonas agar $\mathrm{P}$ medium. Figure S3: SDS-PAGE and zymography assays of the bacterial lysate from $P$. aeruginosa strain RBS. Figure S4: initial velocity as a function of DQ-substrates $(\mu \mathrm{g} / \mathrm{mL})$. (Supplementary Materials) 


\section{References}

[1] R. Lavenir, S. M.-C. Petit, N. Alliot et al., "Structure and fate of a Pseudomonas aeruginosa population originating from a combined sewer and colonizing a wastewater treatment lagoon," Environmental Science and Pollution Research, vol. 21, no. 8, pp. 5402-5418, 2014.

[2] J. Klockgether and B. Tümmler, "Recent advances in understanding Pseudomonas aeruginosa as a pathogen," F1000Research, vol. 6, p. 1261, 2017.

[3] F. Salm, M. Deja, P. Gastmeier et al., "Prolonged outbreak of clonal MDR Pseudomonas aeruginosa on an intensive care unit: contaminated sinks and contamination of ultra-filtrate bags as possible route of transmission?," Antimicrobial Resistance and Infection Control, vol. 5, no. 1, p. 53, 2016.

[4] J. Lee and L. Zhang, "The hierarchy quorum sensing network in Pseudomonas aeruginosa," Protein \& Cell, vol. 6, no. 1, pp. 26-41, 2015.

[5] M. F. Moradali, S. Ghods, and B. H. A. Rehm, "Pseudomonas aeruginosa lifestyle: a paradigm for adaptation, survival, and persistence," Frontiers in Cellular and Infection Microbiology, vol. 7, p. 39, 2017.

[6] B. W. Brunelle, B. L. Bearson, S. M. D. Bearson, and T. A. Casey, "Multidrug-resistant Salmonella enterica Serovar Typhimurium isolates are resistant to antibiotics that influence their swimming and swarming motility," MSphere, vol. 2, no. 6, pp. e00306-e00317, 2017.

[7] E. Sun, E. E. Gill, R. Falsafi, A. Yeung, S. Liu, and R. E. W. Hancock, "Broad-spectrum adaptive antibiotic resistance associated with Pseudomonas aeruginosa mucin-dependent surfing motility," Antimicrobial Agents and Chemotherapy, vol. 62, no. 9, article e00848, 2018.

[8] M. Saffari, S. Karami, F. Firoozeh, and M. Sehat, "Evaluation of biofilm-specific antimicrobial resistance genes in Pseudomonas aeruginosa isolates in Farabi Hospital," Journal of Medical Microbiology, vol. 66, no. 7, pp. 905-909, 2017.

[9] R. Sorde, A. Pahissa, and J. Rello, "Management of refractory Pseudomonas aeruginosa infection in cystic fibrosis," Infection and Drug Resistance, vol. 4, pp. 31-41, 2011.

[10] Z. Pang, R. Raudonis, B. R. Glick, T.-J. Lin, and Z. Cheng, "Antibiotic resistance in Pseudomonas aeruginosa : mechanisms and alternative therapeutic strategies," Biotechnology Advances, vol. 37, no. 1, pp. 177-192, 2019.

[11] S. Jayaseelan, D. Ramaswamy, and S. Dharmaraj, "Pyocyanin: production, applications, challenges and new insights," World Journal of Microbiology and Biotechnology, vol. 30, no. 4, pp. 1159-1168, 2014.

[12] F. Casilag, A. Lorenz, J. Krueger, F. Klawonn, S. Weiss, and S. Häussler, "The LasB elastase of Pseudomonas aeruginosa acts in concert with alkaline protease AprA to prevent flagellin-mediated immune recognition," Infection and Immunity, vol. 84, no. 1, pp. 162-171, 2015.

[13] M. M. Thayer, K. M. Flaherty, and D. B. McKay, "Threedimensional structure of the elastase of Pseudomonas aeruginosa at 1.5-A resolution," The Journal of Biological Chemistry, vol. 266, no. 5, pp. 2864-2871, 1991.

[14] U. Baumann, S. Wu, K. M. Flaherty, and D. B. McKay, "Threedimensional structure of the alkaline protease of Pseudomonas aeruginosa: a two-domain protein with a calcium binding parallel beta roll motif," The EMBO Journal, vol. 12, no. 9, pp. 3357-3364, 1993.
[15] M. Petukh and E. Alexov, "Ion binding to biological macromolecules," Asian Journal of Physics, vol. 23, pp. 735-744, 2014.

[16] U. Edwards, T. Rogall, H. Blöcker, M. Emde, and E. C. Böttger, "Isolation and direct complete nucleotide determination of entire genes. Characterization of a gene coding for $16 \mathrm{~S}$ ribosomal RNA," Nucleic Acids Research, vol. 17, no. 19, pp. 7843-7853, 1989.

[17] D. R. Zerbino and E. Birney, "Velvet: algorithms for de novo short read assembly using de Bruijn graphs," Genome Research, vol. 18, no. 5, pp. 821-829, 2008.

[18] A. M. Kollaran, S. Joge, H. S. Kotian et al., "Context-Specific Requirement of Forty-Four Two-Component Loci in Pseudomonas aeruginosa Swarming," IScience, vol. 13, pp. 305-317, 2019.

[19] G. A. O'Toole, "Microtiter dish biofilm formation assay," Journal of Visualized Experiments, vol. 47, p. 2437, 2011.

[20] A. W. Bauer, W. M. M. Kirby, J. C. Sherris, and M. Turck, "Antibiotic susceptibility testing by a standardized single disk method," American Journal of Clinical Pathology, vol. 45, no. 4_ts, pp. 493-496, 1966.

[21] T. Rasamiravaka, O. M. Vandeputte, L. Pottier et al., "Pseudomonas aeruginosa biofilm formation and persistence, along with the production of quorum sensing-dependent virulence factors, are disrupted by a triterpenoid coumarate ester isolated from Dalbergia trichocarpa, a tropical legume," PLoS One, vol. 10, no. 7, article e0132791, 2015.

[22] A. A. Kembhavi, D. J. Buttle, C. G. Knight, and A. J. Barrett, "The Two Cysteine Endopeptidases of Legume Seeds: Purification and Characterization by Use of Specific Fluorometric Assays," Archives of Biochemistry and Biophysics, vol. 303, no. 2, pp. 208-213, 1993.

[23] F. W. Studier, "Protein production by auto-induction in highdensity shaking cultures," Protein Expression and Purification, vol. 41, no. 1, pp. 207-234, 2005.

[24] Y. Piwpankaew, S. Sakulsirirat, S. Nitisinprasert, T. H. Nguyen, D. Haltrich, and S. Keawsompong, "Cloning, secretory expression and characterization of recombinant $\beta$-mannanase from Bacillus circulans NT 6.7," Springerplus, vol. 3, no. 1, p. 430, 2014.

[25] K. Huynh and C. L. Partch, "Analysis of protein stability and ligand interactions by thermal shift assay," Current Protocols in Protein Science, vol. 79, no. 1, pp. 28.9.1-28.9.14, 2015.

[26] K. N. Van, T. N. Vu, H. N. T. Thuy, and D. Le Van, "Mutations in the gyrA, parC, and mexR genes provide functional insights into the fluoroquinolone-resistant Pseudomonas aeruginosa isolated in Vietnam," Infection and Drug Resistance, vol. Volume 11, pp. 275-282, 2018.

[27] O. Ciofu and T. Tolker-Nielsen, "Tolerance and resistance of Pseudomonas aeruginosa biofilms to antimicrobial agentshow P. aeruginosa can escape antibiotics," Frontiers in Microbiology, vol. 10, p. 913, 2019.

[28] S. M. Soto, "Role of efflux pumps in the antibiotic resistance of bacteria embedded in a biofilm," Virulence, vol. 4, no. 3, pp. 223-229, 2014.

[29] J.-P. Pirnay, S. Matthijs, H. Colak et al., "Global Pseudomonas aeruginosa biodiversity as reflected in a Belgian river," Environmental Microbiology, vol. 7, no. 7, pp. 969-980, 2005.

[30] Y. H. Cho, S. J. Kim, J. Y. Kim, D. H. Lee, K. Park, and Y. C. Park, "Effect of PelB signal sequences on Pfel expression and $\omega$-hydroxyundec-9-enoic acid biotransformation in 
recombinant Escherichia coli," Applied Microbiology and Biotechnology, vol. 102, no. 17, pp. 7407-7416, 2018.

[31] B. Jaouadi, N. Zaraî Jaouadi, H. Rekik et al., "Biochemical and molecular characterization of Pseudomonas aeruginosa CTM50182 organic solvent-stable elastase," International Journal of Biological Macromolecules, vol. 60, pp. 165-177, 2013.

[32] T. J. Dolinsky, J. E. Nielsen, J. A. McCammon, and N. A. Baker, "PDB2PQR: an automated pipeline for the setup of PoissonBoltzmann electrostatics calculations," Nucleic Acids Research, vol. 32, pp. W665-W667, 2004.

[33] N. H. Khan, M. Ahsan, W. D. Taylor, and K. Kogure, "Culturability and survival of marine, freshwater and clinical Pseudomonas aeruginosa," Microbes and Environments, vol. 25, no. 4, pp. 266-274, 2010.

[34] V. Rutherford, K. Yom, E. A. Ozer et al., "Environmental reservoirs for exoS+ and exoU+ strains of Pseudomonas aeruginosa," Environmental Microbiology Reports, vol. 10, no. 4, pp. 485-492, 2018.

[35] R. Thabet, V. Leignel, H. Ayadi, and E. Tastard, "Interannual and seasonal effects of environmental factors on the zooplankton distribution in the solar saltern of Sfax (south-western Mediterranean sea)," Continental Shelf Research, vol. 165, pp. 1-11, 2018.

[36] A.-L. Michon, E. Jumas-Bilak, R. Chiron, B. Lamy, and H. Marchandin, "Advances toward the elucidation of hypertonic saline effects on Pseudomonas aeruginosa from cystic fibrosis patients," PLoS One, vol. 9, no. 2, p. e90164, 2014.

[37] A. H. Tart and D. J. Wozniak, "Shifting paradigms in Pseudomonas aeruginosa biofilm research," in Current Topics in Microbiology and Immunology, T. Romeo, Ed., vol. 322, pp. 193-206, Springer Berlin Heidelberg, Berlin, Heidelberg, 2008.

[38] M. M. A. A. El-Gendy, H. A. A. Al-Zahrani, N. Y. Abozinadah, and A. M. A. El-Bondkly, "In vivo evaluation of the toxic effect of ethyl acetate extracts of marine antibiotic resistance Pseudomonas species derived from the Red Sea," Applied Biochemistry and Biotechnology, vol. 184, no. 1, pp. 323-349, 2018.

[39] W.-S. Chang, M. van de Mortel, L. Nielsen, G. Nino de Guzman, X. Li, and L. J. Halverson, "Alginate production by Pseudomonas putida creates a hydrated microenvironment and contributes to biofilm architecture and stress tolerance under water-limiting conditions," Journal of Bacteriology, vol. 189, no. 22, pp. 8290-8299, 2007.

[40] D. H. Limoli, C. J. Jones, and D. J. Wozniak, "Bacterial extracellular polysaccharides in biofilm formation and function," Microbiology Spectrum, vol. 3, no. 3, 2015.

[41] A. C. M. Galdino, M. P. de Oliveira, T. C. Ramalho, A. A. de Castro, M. H. Branquinha, and A. L. S. Santos, "Anti-virulence strategy against the multidrug-resistant bacterial pathogen Pseudomonas aeruginosa: Pseudolysin (elastase B) as a potential druggable target," Current Protein \& Peptide Science, vol. 20, no. 5, pp. 471-487, 2019.

[42] J. Overhage, M. Bains, M. D. Brazas, and R. E. W. Hancock, "Swarming of Pseudomonas aeruginosa is a complex adaptation leading to increased production of virulence factors and antibiotic resistance," Journal of Bacteriology, vol. 190, no. 8, pp. 2671-2679, 2008.

[43] J. Overhage, S. Lewenza, A. K. Marr, and R. E. W. Hancock, "Identification of genes involved in swarming motility using a Pseudomonas aeruginosa PAO1 mini-Tn5-lux mutant library," Journal of Bacteriology, vol. 189, no. 5, pp. 2164 2169, 2007.

[44] F. Hang, Q. Wang, Q. Hong, C. Gao, H. Zhang, and W. Chen, "Structural insight into a novel neutral metalloproteinase from Paenibacillus spp. BD3526: Implications for mechanisms of rapid inactivation and calcium- dependent stability," International Journal of Biological Macromolecules, vol. 95, pp. 1082-1090, 2017.

[45] W. Maret and Y. Li, "Coordination dynamics of zinc in proteins," Chemical Reviews, vol. 109, no. 10, pp. 4682-4707, 2009. 